\title{
Overvoltage in the free phase of the stator winding in case of asymmetric short circuit implicit pole synchronous generator biaxial excitation
}

\author{
Nurali Pirmatov ${ }^{1, *}$, Sherzod Toshev ${ }^{1}$ \\ ${ }^{1}$ Tashkent State Technical University named after I. Karimova, 100095, Tashkent, Uzbekistan \\ Joint stock company Uzbekgidroenergokurulish, 100077, Tashkent, Uzbekistan
}

\begin{abstract}
Reviewed and analyzed issues associated with overvoltage in the free phase winding of the stator with asymmetric short-circuit implicitly pole synchronous generator biaxial excitation, and compared the results of experimental measurements of the phase currents in the study of a mathematical model of the synchronous generator biaxial excitation (MM SGBD) and physical model SGBD and the SG at steady-state single-phase short circuit.
\end{abstract}

\section{Introduction}

In order to conduct a comparative analysis of the research results of the developed mathematical model of synchronous generator biaxial excitation (SGBD) with experimental data, two physical models were adopted: an implicit pole synchronous generator (SG) and SGBD, converted from MTO-12-4 type induction motors, with a power of 2, $2 \mathrm{~kW}$, voltage 220/380 V (Fig. 1).

An important place in the development strategy of the electric power industry is occupied by generators that produce electrical energy. The problems of managing transients of synchronous generators, primarily in terms of optimizing the processes of the generator, from the standpoint of energy-saving and minimizing costs, is an important task.

An effective way to solve the above problem is to convert mechanical energy into electrical synchronous generators biaxial excitation (SGBD) and asynchronous synchronous generators (ASTG). In this regard, in recent years there has been a growing interest of engineers and researchers to these machines, which can fully solve the tasks.

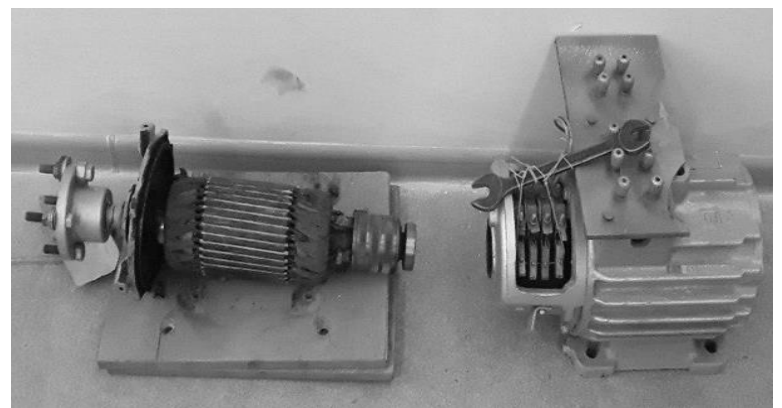

Fig. 1. General view of a synchronous biaxial excitation generator

Of great importance is the study of asymmetric modes of SGBD with the network. At the same time, there are a number of specific issues of joint work of the SRS with the electric network.

\section{Discussion}

Studies of the mathematical model and the physical model of SGBD, as well as SG in short circuit modes, were carried out.

With a single-phase short circuit:

$$
U_{a}=0, i_{b}=i_{c}=0
$$

Then we write the equations of flux linkage of the stator winding in the form $[2,3,4]$ :

$$
\left.\begin{array}{l}
\frac{d \psi_{d}}{d t}-\omega_{r} \cdot \psi_{q}-\left(2 r_{c}+3 r_{k}\right) \cdot i_{d}=0 \\
\frac{d \psi_{q}}{d t}+\omega_{r} \cdot \psi_{d}-\left(2 r_{c}+3 r_{k}\right) \cdot i_{q}=0
\end{array}\right\}
$$

The equations of flux linkages of the stator chain are as follows $[5,6,7]$ :

$$
\left.\begin{array}{l}
\psi_{d}=X_{a d} \cdot\left(1+\cos 2 \gamma_{r}\right) \cdot\left(i_{f d}+i_{1 d}\right)- \\
-X_{a d} \cdot \sin 2 \gamma_{r}\left(i_{f q}+i_{1 q}\right)-2\left(X_{d}+X_{k}\right) \cdot i_{d} \\
\psi_{q}=-X_{a d} \cdot \sin 2 \gamma_{r} \cdot\left(i_{f d}+i_{1 d}\right)- \\
-X_{a q} \cdot\left(1-\cos 2 \gamma_{r}\right) \cdot\left(i_{f q}+i_{1 q}\right)-2\left(X_{d}+X_{k}\right) \cdot i_{q}
\end{array}\right\}
$$

We write the flux linkage in the single-phase short circuit mode in matrix form $[8,9]$ :

\footnotetext{
${ }^{*}$ Corresponding author: tshe100679@gmail.com
} 

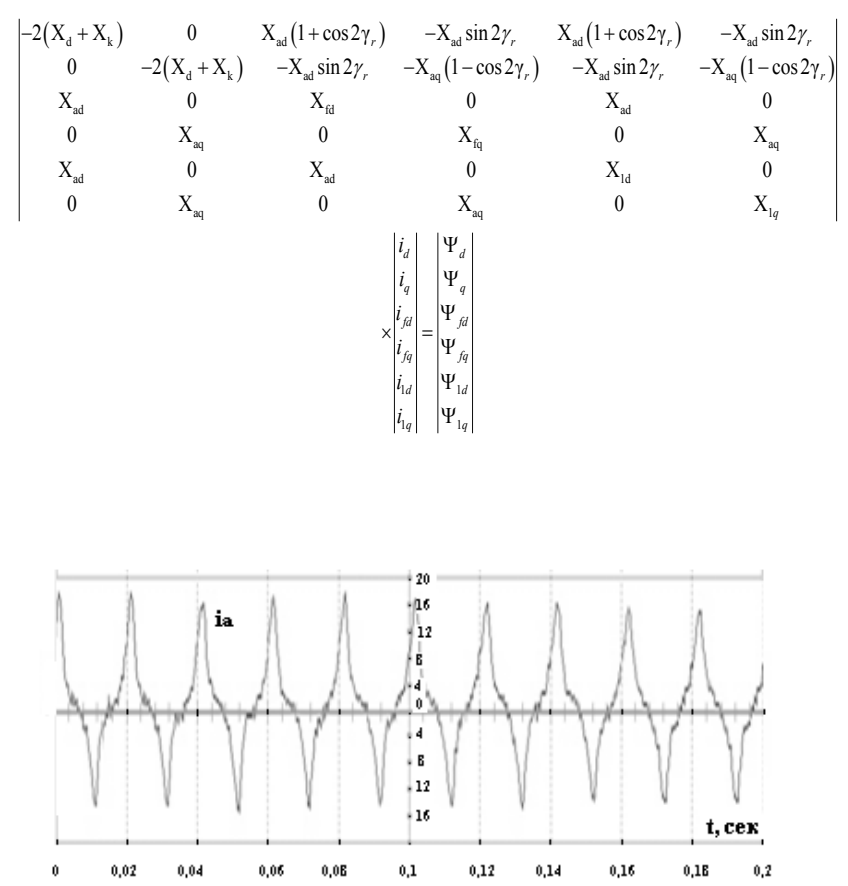

a)

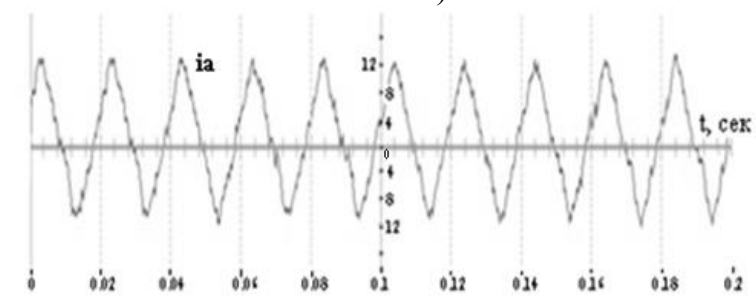

b)

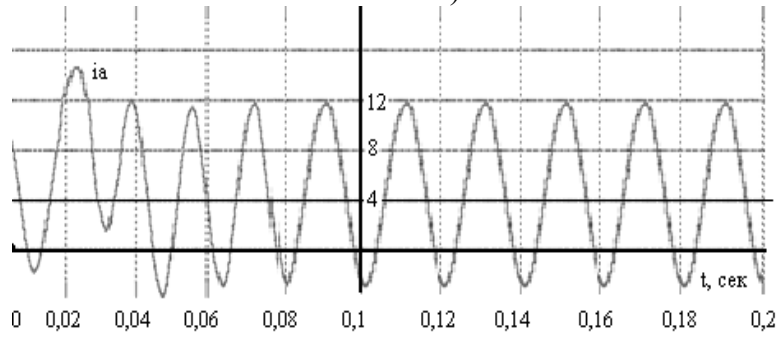

c)

Fig. 2. Oscillogram of stator currents (a) $S G$ ia $=17.3$ p.u. and (b) SGBD ia $=12.1$ p.u., c) MM SGBD ia $=13$ p.u. at singlephase short circuit

As is known, in the asymmetric short circuit mode, overvoltage occurs in the free phase of the stator winding of the SGBD. This is due to electrical and magnetic asymmetry in the rotor circuit of the machine.

For an asymmetric short circuit, the SGBD coefficients in the differential equations become time-dependent, which leads to an increase in the voltage in the free phase of the stator winding for a certain ratio of circuit parameters. In this case, the magnetic field created by the introduced transverse excitation winding prevents the voltage increase (Fig. 3), [1].

The initial value of the voltage in the free phase of the stator winding depends on the scattering magnetic flux, and not on the total total magnetic flux. The subsequent change in voltage depends on the constant time of the field winding and the stator. To avoid overvoltage, the direction of the magnetic flux of the transverse excitation winding should be selected so that when the main magnetic field of the stator is exposed, the magnetic field of scattering is minimal.

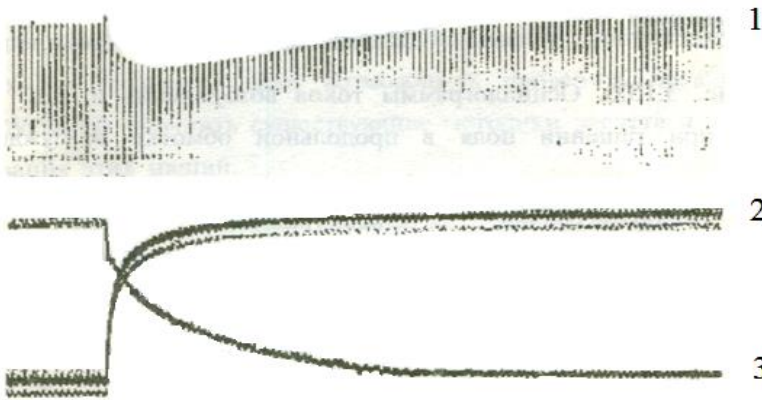

1

2

Fig. 3. Oscillogram of EMF (1), longitudinal current $i_{f d}(3)$ and current transverse $\mathrm{i}_{\mathrm{fq}}(2)$ of the field winding

The increase in the scattering of the stator magnetic flux depends on the free currents in the rotor windings. The additional magnetic flux created by these free currents is oriented in the same direction as the magnetic fluxes of the field winding, which prevents the passage of the magnetic flux of the stator. The larger the drop in the magnetic voltage in the rotor winding (scattering of the magnetic field energy), the lower the EMF induced in the free phase of the stator winding and decrease into the flux $[7,8,9]$. Limitations for single-phase short circuit [10]:

$$
\left.\begin{array}{l}
U_{a}=0 \\
i_{b}=0 \\
i_{c}=0
\end{array}\right\}
$$

We determine the voltage of phases $\mathrm{B}$ and $\mathrm{C}$ from the expression:

$$
\begin{gathered}
U_{b}=\frac{d \psi_{b}}{d t}-r_{c} i_{b} \\
U_{c}=\frac{d \psi_{c}}{d t}-r_{c} i_{c} \\
U_{b}=\frac{d \psi_{b}}{d t} \\
U_{c}=\frac{d \psi_{c}}{d t}
\end{gathered}
$$

here

$\psi_{b}=\psi_{d} \cos \left(\gamma-120^{\circ}\right)-\psi_{q} \sin \left(\gamma-120^{\circ}\right)+\psi_{0}$

$\psi_{c}=\psi_{d} \cos \left(\gamma+120^{\circ}\right)-\psi_{q} \sin \left(\gamma+120^{\circ}\right)+\psi_{0}$

here $\gamma_{0}$ - the angle between the phase magnetic axis of phase A and the axis of the rotor. For single phase short circuit:

$U_{b}=\left(\frac{d \psi_{d}}{d t}-\psi_{q}\right) \cos \left(\gamma-120^{\circ}\right)-\left(\frac{d \psi_{q}}{d t}+\psi_{d}\right) \sin \left(\gamma-120^{\circ}\right)$

$U_{c}=\left(\frac{d \psi_{d}}{d t}-\psi_{q}\right) \cos \left(\gamma+120^{\circ}\right)-\left(\frac{d \psi_{q}}{d t}+\psi_{d}\right) \sin \left(\gamma+120^{\circ}\right)$

$\psi_{d}, \psi_{q}$ - according to equation (4) for a single-phase short circuit mode, respectively. 


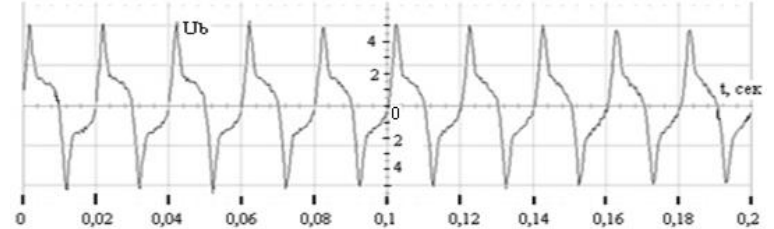

a)

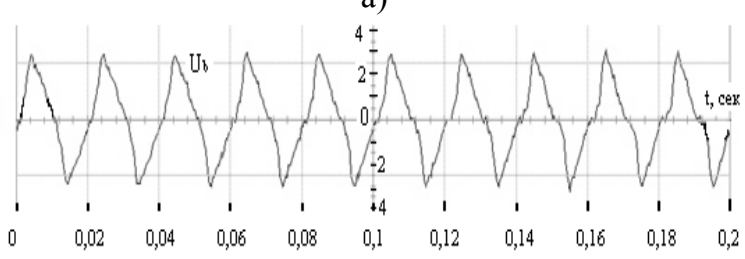

b)

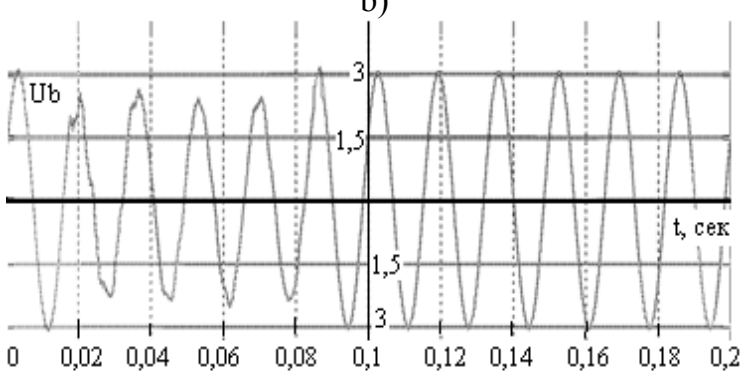

c)

Fig. 4. Oscillogram of the overvoltage of the free phase of the stator (a) $\mathrm{SG}(\mathrm{U}=30 \mathrm{~V}(1 \mathrm{pu}), \mathrm{Ub} .=142 \mathrm{~V}(4.73 \mathrm{pu}))$ and (b) SGBD (U $=30 \mathrm{~V}$ ( 1 p.u.) $\mathrm{Ub}=85.2 \mathrm{~V}(2.84 \mathrm{pu})$, (c) MM $\operatorname{SGBD}(\mathrm{U}=30 \mathrm{~V}(1 \mathrm{pu}), \mathrm{Ub}=90 \mathrm{~V}(3 \mathrm{pu})$ for single-phase short circuit

\section{Comparative results}

In the table. Figures 1 and 2 present the results of experimental measurements of phase currents and overvoltage in the free phase of the stator winding, in which the mathematical model under study of the synchronous generator biaxial excitation (MM SGBD) corresponds to the physical model of SGBD and SG with a steady state single-phase short circuit.

Comparisons of the results of experimental measurements of SG and calculation of the stator phase winding current on the mathematical model of SGBD and for single-phase short-circuit are given in Table 1.

Table 1.

\begin{tabular}{|c|c|c|c|c|c|}
\hline & \multicolumn{5}{|c|}{ Stator phase currents } \\
\hline & \multicolumn{2}{|c|}{ Steady state } & \multicolumn{2}{|c|}{ Short Circuit } & \multirow{2}{*}{$\begin{array}{l}\text { Multip } \\
\text { licity }\end{array}$} \\
\hline & Ampere & $\mathrm{pu}$ & Ampere & $\mathrm{pu}$ & \\
\hline SG & 7,0 & 1,0 & 121,18 & $\begin{array}{c}17,31 \\
2\end{array}$ & 17,312 \\
\hline SGBD & 6,9 & 0,98 & 83,5 & 12,1 & 12,1 \\
\hline $\begin{array}{c}\text { MM } \\
\text { SGBD }\end{array}$ & 7,0 & 1,0 & 91 & 13 & 13 \\
\hline
\end{tabular}

From tables 1 and 2 it follows that:

- by turning on the transverse excitation winding of a synchronous biaxial excitation generator, a reduction in current and overvoltage in modes with a single-phase short circuit is achieved. generators almost doubled;

- the currents of a single-phase short circuit in the experimental SGDV installation and in the solutions of MM SGBD are the same. These statements are confirmed by the taken oscillograms of short-circuit currents during experimental studies of SG and SGBD, which are shown in Fig. 2.

Table 2. Comparison table of overvoltages in modes at single-phase short-circuit generators

\begin{tabular}{|c|c|c|c|c|c|}
\hline & \multicolumn{4}{|c|}{ Voltage } \\
\hline & \multicolumn{2}{|c|}{$\begin{array}{c}\text { Steady } \\
\text { state }\end{array}$} & \multicolumn{2}{c|}{$\begin{array}{c}\text { Free phase } \\
\text { overvoltages }\end{array}$} & Multiplicity \\
\hline & B & o.e. & B & o.e. & \\
\hline SG & 30 & 1,0 & 142 & 4,73 & 4,73 \\
\hline SGBD & 30 & 1,0 & 85,2 & 2,84 & 2,84 \\
\hline MM & 30 & 1,0 & 90 & 3 & 3 \\
SGBD & & & & & \\
\hline
\end{tabular}

- overvoltage on the free phase of the stator winding during a single-phase short-circuit in the experimental installation of SGDV and in the solutions of MM SGBD are the same. These statements are confirmed by the recorded waveforms of the overvoltage in the free phase of the stator winding during experimental studies of SG and SGBD, which are shown in Fig. 4.

\section{Conclusion}

The proposals outlined in this paper offer the prospect of further research is an extremely important problem - the estimation of the surge in the free phase winding of the stator with asymmetric short-circuit implicitly pole synchronous generator biaxial excitation.

\section{References}

1. Akhmatov M. G. Synchronous machines. Special course. - Moscow: higher school, 136 (1984)

2. Khaidarov S.Zh., Toshev Sh.E. - Bulletin of TSTUniversity. 1, 68-74 (2016)

3. Chernykh I.V. DMK Press; St. Petersburg: Peter, 288 (2008)

4. Allaev K.R., Khaidarov S.D. Izv. Academy of Scien. of Uzb., a series of tech. // Science, 5, 23-26 (1986)

5. Pirmatov N.B., Salimov D.S., Toshev Sh.E. - J. of Prob. of Energy and Resour. S. 1-2, 163-165 (2012)

6. Toshev Sh.E., Taniev M., Egamberdiev D.Kh. - The Repub. of scien. and tech. conf. - Fargana, 182-184 (2016)

7. Pirmatov N.B., Toshev Sh.E. - Bulletin of the Almaty Ins. of Ener. and Communi. 2(2), 40-44 (2008)

8. Pirmatov N.B., Toshev Sh.E., Haydarov S.D., Tosheva Sh.N. Europ. Conf. on Inn. in Tech. and Natu. Scien.:, $15^{\text {th }}$ Int. scien. conf.. 105-110 (2017)

9. Toshev Sh.E., Pirmatov N.B., Haydarov S.D., Duvlonov J.N., Yakubova D.K. Europ. Scien. R.:Aust, Vienna,11-12, 134-136 (2016)

10. Pirmatov N.B., Toshev Sh.E. - Int. Scien. and tech. conf. Collection of works. Tashkent.: 175-177 (2006) 